\title{
Capstone Project in a Freshman Solid Modeling Course
}

\section{Dr. John A. Mirth, Rose-Hulman Institute of Technology}

John Mirth has 23 years of experience teaching in a primarily undergraduate environment. This experience includes time at the University of Denver, the University of Wisconsin-Platteville, and his current position at Rose-Hulman Institute of Technology. He has a BSME degree from Ohio University, and MSME and Ph.D. degrees from the University of Minnesota.

\section{Dr. John P Iselin, University of Wisconsin, Platteville}

John P Iselin is a professor of mechanical engineering at The University of Wisconsin Platteville. Dr. Iselin's interests are in Computational Fluid Dynamics and undergraduate pedagogy. 


\title{
Capstone Project in a Freshman Solid Modeling Course
}

\begin{abstract}
This paper examines the use of rapid prototyping technology to introduce underclass mechanical engineering students to topics associated with their future studies. The course environment is an introductory modeling course where students study solid modeling and perform reverse engineering studies on several mechanical systems. The focus of this paper is a capstone project for the course where students design and build a blower for the purpose of inflating an air mattress. The project provides students with a tangible introduction to several topics that are important for their continuing studies. These topics include developing a better understanding of the relationship between computer models and physical models, the effect of manufacturing tolerances on design decisions, and an introduction to concepts in fluid flow.

The project takes place during the final 3-4 weeks of the course with students working in teams of three. Each student in the team designs a separate component for a 3 piece blower. The components are then prototyped using a fused deposition modeling (FDM) process. The prototyped parts are assembled with a motor and tested to examine the performance of the models. The prototype and testing process provides an early experience in design, manufacturing, and fluid flow topics. From a design aspect, students get the opportunity to hold the models that were generated on the computer. This provides students with an initial exposure to how size and geometry relationships are perceived in a virtual environment compared to their actual physical size. A manufacturing aspect is revealed in the process by the need to consider design tolerances to mate the parts with one another as well as the need to be able to secure an off-the-shelf motor in the assembly. Early exposure to fluid dynamics concepts are introduced as finer design points such as a volute, diffuser, and Venturi are discussed through computational fluid dynamics analysis. Finally, the students are exposed to structured experimental procedures to determine the flow rate and maximum pressure capabilities of each blower. The end result of the project is the ability to provide freshman engineering students with an introduction to several important mechanical engineering topics in a relatively short time frame.
\end{abstract}

\section{Introduction}

One of the challenges of developing a cohesive engineering curriculum is that of providing students with experiences that will engage them with relevant engineering problems at an early point in their education. A number of popular approaches exist for engaging freshman students in their early studies. Samples of these approaches include freshman engineering design courses that introduce students to the design process, ${ }^{1,2}$ courses that are built upon on reverse engineering projects, ${ }^{3}$ and others that combine these ideas with computer modeling and/or prototyping of products. ${ }^{4-6}$

The course described in this paper has many of the same aspects as the various styles of courses cited above. This paper describes a freshman-level course that introduces students to their chosen major (mechanical engineering) using the combination of solid modeling and reverse engineering as the foundation of the course. The culmination of the course, upon which this 
paper will focus, is a student project wherein the students combine the aspects of reverse engineering, modeling, and rapid prototyping to create and test a working prototype of a device to inflate air mattresses. This project is used to provide a tangible design experience for the students while also introducing students to topics in manufacturing, fluid dynamics, and experimentation that students will encounter in their ongoing studies.

The following sections provide more detail on the course and the final project that forms the focal point for this paper. The course environment is first described along with the placement of the final project within the course. This is followed by an examination of the design and manufacturing ideas to which the students are exposed through the project. A third section examines how an initial exposure to fluid dynamics is interwoven into the design process to persuade students to think more deeply about why and how their design functions. This is followed by the description of a structured experiment to provide students with an introduction to the systematic testing of devices as well as additional instruction in fluid dynamics.

\section{Engineering Modeling and Design - The Course Environment}

The project described within this paper is part of the "Engineering Modeling and Design” course at the University of Wisconsin-Platteville. The course serves as an entry-level engineering course for mechanical engineering majors. Students typically take the course concurrently with their enrollment in either Calculus I or Calculus II. The course format consists of a combination of solid modeling and the use of reverse engineering to introduce students to the function and operation of mechanical systems. The course is a 3 credit course that meets 4 hours per week.

The culmination of the above course is a "design and prototype" project that is integrated into the final four weeks of the course. Students are challenged to design and prototype a blower similar to the Coleman Quick Pump ${ }^{\circledR}$ shown in Fig. 1. The students design and prototype the top and bottom housings, and the impeller for a blower, as shown in Fig. 2, with the motor and nozzle being provided to the students to complete their assembly. Prototypes are created via Fused Deposition Modeling (FDM) on a Dimension SST 1200 machine.

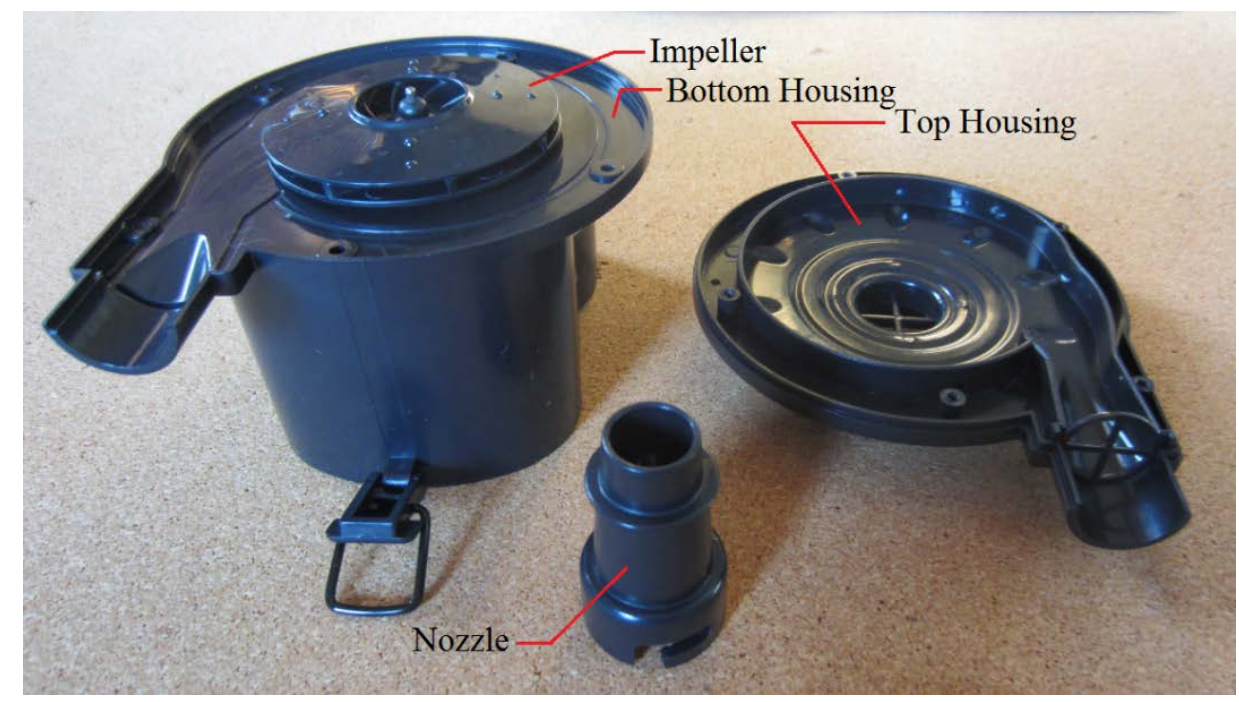

Figure 1: A Coleman Quick Pump ${ }^{\circledR}$ 


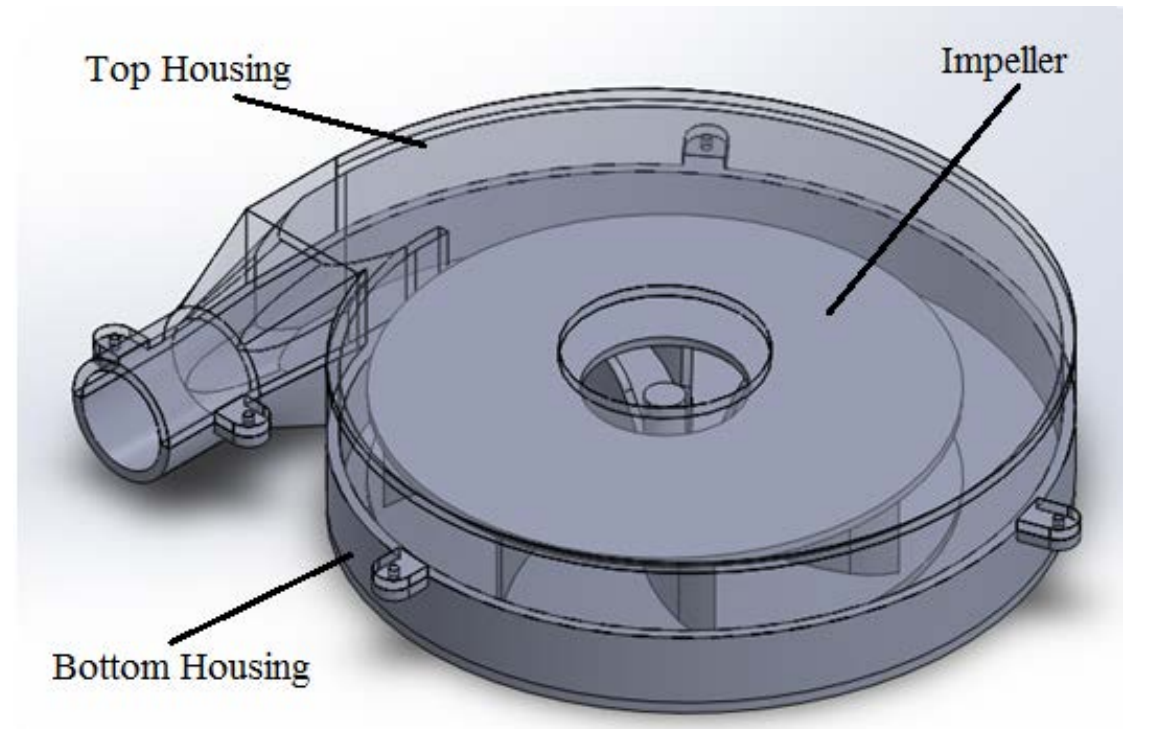

Figure 2: An Example of Student Designed Components for the Blower

Prototypes are limited to a maximum of 5 cubic inches of build material. This limit is imposed to reduce print time and material cost. The cost of the print materials is covered by the departmental budget.

The blower project has been specifically designed to provide students with an early exposure to concepts in both manufacturing and fluid flow. The next sections provide more detail on how the project is framed by these topics.

\section{Establishing the Relationship between Design and Manufacturing}

The blower project has several salient features that provide value to freshmen engineering students. The first of these is the opportunity to develop an understanding of the relationship between modeling and manufacturing. The students face two primary manufacturing challenges in the blower design process - the need to consider manufacturing tolerances and the need to consider manufacturing limitations.

The Dimension SST machine used to create the prototypes has a stated build tolerance of \pm 0.01 inches. This is a relatively loose tolerance in comparison with the tolerances used in building the commercial versions of the blower. As such, students cannot expect to copy the commercial products in terms of fitting and securing the parts to one another. Table 1 lists the four interfaces the students need to reproduce. The table also compares how these interfaces are satisfied in the commercial blower with how students approach the development of the interfaces.

Two of the assembly interfaces from the original product are typically maintained by the students. The force fit between the motor and impeller is created by introducing a second manufacturing step where the students drill the hole in the impeller after prototyping. The locking tapered fit between the nozzle and blower can also be reasonably reproduced due to the existence of the taper. 
Table 1: A comparison of interfaces between parts.

\begin{tabular}{|l|l|l|}
\hline Interface & Commercial Blower & Student Blower Interface Examples \\
\hline Nozzle to Housing & Tapered fit with locking tabs & Tapered fit with locking tabs \\
\hline Motor to Impeller & Force fit & $\begin{array}{l}\text { Force fit - typically drilled out after prototype } \\
\text { is made }\end{array}$ \\
\hline Motor to Housing & Two screws & $\begin{array}{l}\text { Loose fit combined with an adhesive such as } \\
\text { hot melt glue. }\end{array}$ \\
\hline $\begin{array}{l}\text { Top to Bottom } \\
\text { Housing }\end{array}$ & $\begin{array}{l}\text { A tight overlapping fit combined with } 5 \\
\text { screws. }\end{array}$ & Flush fits secured by screws \\
\hline
\end{tabular}

The larger tolerances on the FDM process do not allow students to reproduce the commercial motor-to-housing or the top-to-bottom housing interfaces. The screws that secure the motor to the housing in the commercial product are too small to accurately locate and place in the FDM produced models, so students need to define an alternative method to secure the motor to the housing. This is often done with the use of an adhesive such as hot melt glue. A common modification to the overlapping fit between the top and bottom housings is to use a flush fit that allows these parts to then be secured with screws.

A final manufacturing challenge is associated with the wall thicknesses that can be reasonably produced by the FDM machine. Students are asked to use a minimum wall thickness of 0.06 inches to maintain the structural integrity of their parts. This limit is somewhat larger than what is found in the commercial product and thus forces students to produce designs that do not exactly match the commercial product. The impeller design is the part most affected by this limitation. The greater wall thickness of the student parts leads naturally to an increase in the size of the impeller. Some groups attempt to keep this size increase as small as possible to closely mimic the commercial version, while other groups show substantial increases in the impeller size under the assumption that a larger impeller will move more air more quickly. Students are limited to a maximum of five cubic inches of material for all of the parts which restricts the maximum size of the impeller.

This section has highlighted some of the manufacturing decisions students need to make in their attempts to reproduce the blower design. The decisions are driven by the need to use a different manufacturing platform than is used to produce the commercial blowers. The limitations of the manufacturing process force students to consider the impact of tolerances, part interfaces, and part geometry, thus providing students with an early exposure to topics related to "design for manufacturing”. The next section continues to examine the introduction of engineering concepts in a freshman course by looking at the role of fluid dynamics in the blower design process.

\section{Investigating the Fluid Dynamics of Blower Design}

In addition to exposing students to some of the manufacturing challenges, this project exposes students to the use of solid modeling as the starting point for numerical simulations, specifically in this case, computational fluid dynamics (CFD). Students do not perform CFD analysis, but the students are presented with the results from a CFD analysis of a generic blower geometry. This provides students with an early introduction to several fluid dynamics concepts. 
Since freshman engineering students have little prior experience with fluid dynamics concepts they are initially ill prepared to grasp some of the more subtle aspects of the blower design. The students almost universally believe that the impeller design is the most critical component and consider the top and bottom housings as simply containers for the impeller.

The group member with the greatest modeling ability and/or enthusiasm typically volunteers to design the impeller. The closed impeller design of the commercial blower is typically mimicked in terms of number of blades and rearward swept blades. This focus on the impeller leads students to overlook the subtle design features in the housing that significantly enhance the blower performance.

After initial designs are developed, students receive feedback from the instructor on topics related to blower design. The housing features of the commercial design shown in Fig. 3 are highlighted and explained. These features include the 1) volute, 2) diffuser and 3) throat. These features are examined after initial design development to allow students to reflect on whether or not they have thought about the effect of the fluid flow features in their initial design concept. Teams seldom incorporate all three of these features in their initial design, and many of them do not include any of the features.

Since the blower is a dynamic machine it requires a conversion from kinetic energy to internal energy in the form of increased pressure. The diverging volute allows this deceleration and commensurate pressure rise to occur. The diffuser is a diverging passage that lowers the pressure in the exit duct and hence creates a pressure gradient that is conducive to the air exiting the blower as opposed to recirculating. Lastly, the throat further decreases the local pressure in the exit duct potentially facilitating more air to exit the blower.

Students are presented with the results of a series of computational simulations, shown in figure 4, that illustrate the compound effects of these three features. The "W/O volute" data are from geometry that did not include any of these housing features. The "W/ volute" data are from geometry that includes the volute but not the other two features. The "Diffuser" data include both the volute and the diffuser, but not the throat. The "Throat" data include all three features.

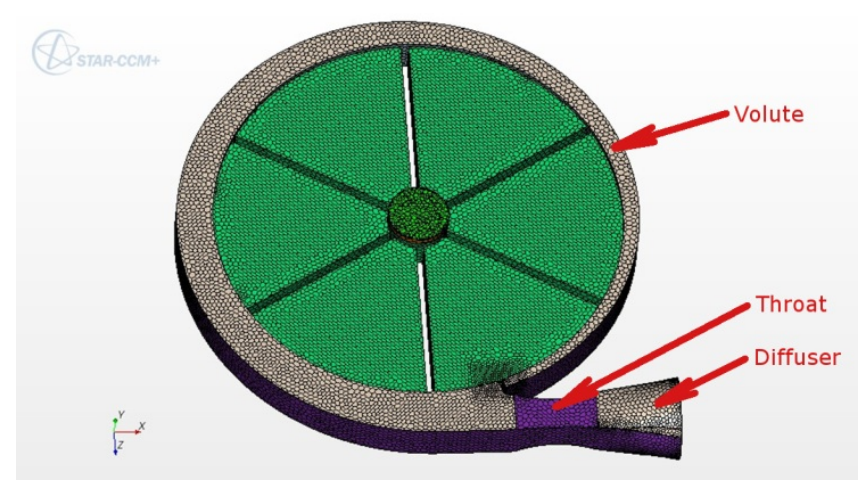

Figure 3: Housing features that are highlighted and explained 


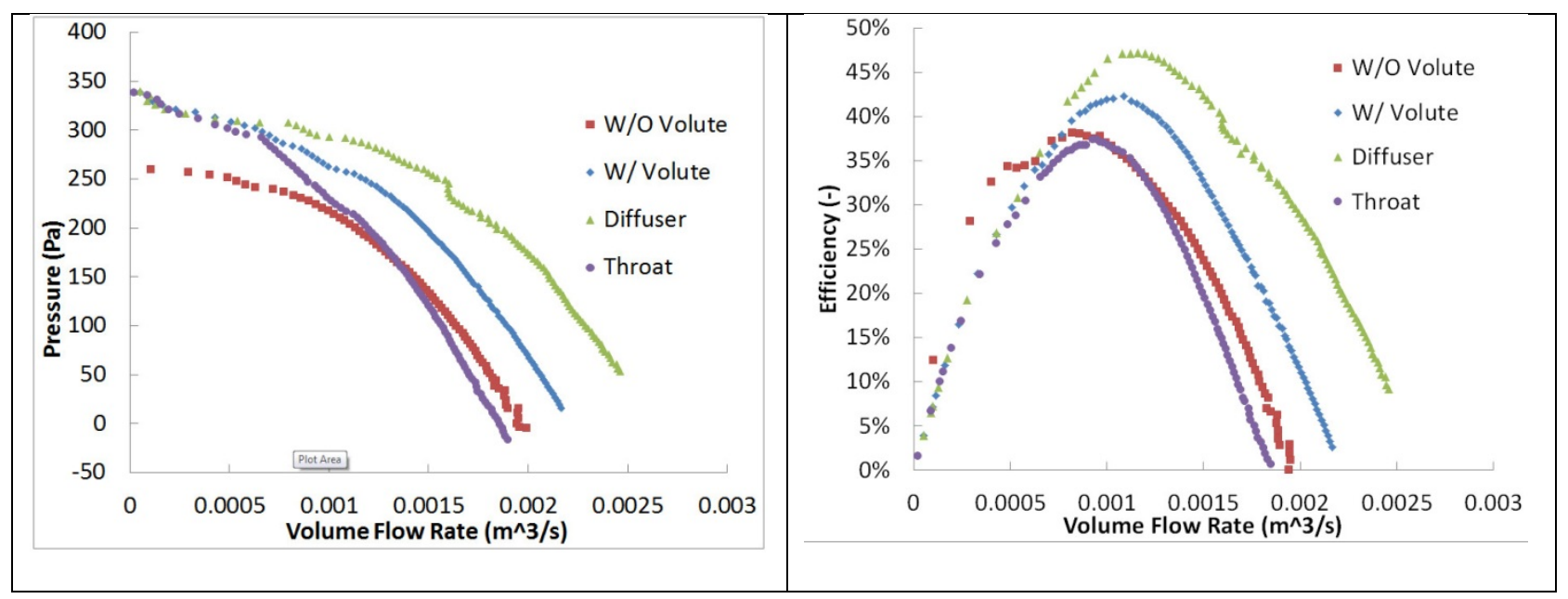

Figure 4: Blower performance and efficiency curves. The W/O Volute configuration contains no volute, diffuser, or throat. The $W$ / Volute configuration contains the volute without the other two features. The Diffuser configuration contains both the volute and diffuser, but not the throat. Lastly, the Throat configuration contains all three features.

The students can clearly see that the volute has increased the dead head pressure of the blower performance curve and the efficiency compared to no volute. The addition of the diffuser has further improved the performance curve and the efficiency. However, the further addition of the throat has reduced the performance and efficiency gains achieved by the volute and diffuser. Further examination of the pressure profiles in the exit region and velocity vector plots, as shown in figure 5, indicate that although the throat has reduced the pressure as desired the ensuing adverse pressure gradient has caused a significant flow separation as compared to the configuration without the throat, thus resulting in the degraded performance when the throat feature was incorporated.

This analysis allows for the explanation of the advantages and disadvantages of creating different pressure gradients in different areas to control the flow characteristics. It also permits the explanation of the effects of separation on device performance. These new insights immediately impact student blower designs. They all typically incorporate a volute into their housing designs, and many incorporate a diffuser.

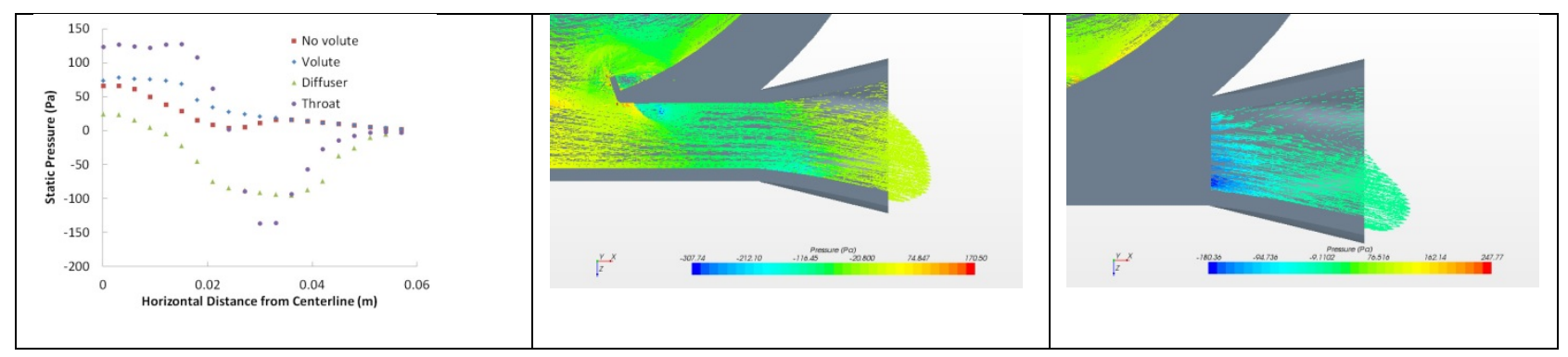

Figure 5: The left panel shows the pressure profiles along the exit portion of the blower for the four configurations. The center panel shows a velocity vector plot of the exit region for the case with the volute and diffuser, but not throat. The right panel shows the velocity vector plot for the configuration with all three features. 
Students learn that understanding some fundamental concepts of fluid flow can help guide them in the design process. This type of early exposure can be leveraged in later courses, like fluid dynamics, to help motivate students in these more advanced courses.

\section{Testing the Final Product - An Introduction to Structured Experimentation}

The student designed blowers are prototyped using an FDM process. Students are then required to assemble and test their blowers in a structured experiment. In lieu of developing fan curves and efficiencies, two simpler tests are conducted to determine the dead head pressure and the volume flow rate.

The dead head pressure is determined by blocking the flow from a nozzle fitted with a static pressure tap (label $\mathrm{C}$ in figure 6). Using a pressure transducer the static pressure is measured while the nozzle exit is blocked. The results from the Spring 2013 semester, which included 9 student groups, varied from 2.8 to 8.0 inches of water.

The second test requires a double sized air mattress be filled until the static blower exit pressure is $80 \%$ of the static dead head pressure. In two cases the blowers failed before this second test could be completed. In one case the force fit from the motor to the impeller failed, and in the other the motor mount failed. Of the seven blowers that completed the test, the fill times varied from 91 to 177 seconds.

The results of the two scores were combined by dividing the dead head pressure by the time to fill the air mattress in seconds. Curiously, the design that produced the greatest dead head pressure (8 inches of water) had the slowest fill time (177 seconds). Students received a minimum of five of the ten points if they were able to complete the dead head pressure test, which in the Spring 2013 semester was all the groups. The remaining 5 points are distributed according to the combined score.

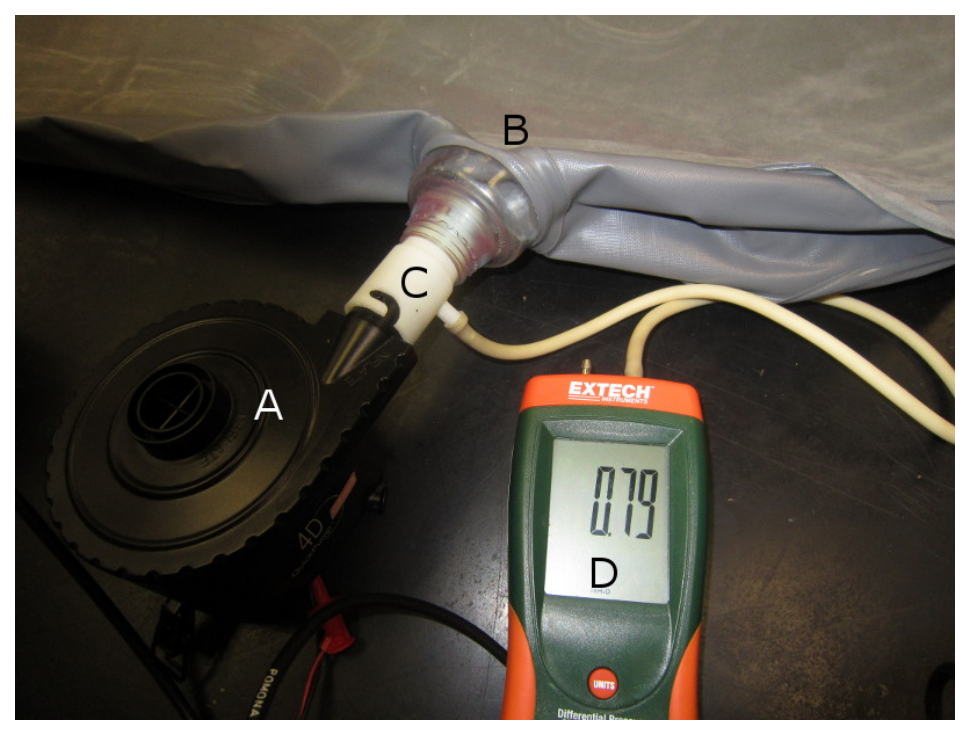

Figure 6: Experimental setup: (A) Blower; (B) Air Mattress; (C) Nozzle fitted with a pressure tap; and (D) Pressure transducer. 
Although the student groups who failed to complete the fill test were somewhat disappointed, all of the groups indicated a sense of accomplishment. Student feedback displayed some initial doubt that they would be able to design and build a blower that would move any amount of air. One of the advantages of this project is that almost any reasonable design will work at some minimal level. This is important to build confidence in beginning engineering students who may have had little prior exposure to any design and manufacturing process.

\section{Logistics}

The preceding sections have focused on the engagement of freshmen students in a capstone design project. This section focuses on some of the project logistics.

The university typically runs 4-6 sections of the Modeling and Design course each semester. Each section contains approximately 25 students for a total of 100-150 students enrolled in the course any given semester. The prototyping machine is housed within and supported by the Mechanical Engineering program. As such, only the course sections taught by Mechanical Engineering faculty participate in this project.

The limited participation is necessary due to the limited access to the prototyping equipment. The course instructor works with the students to download and print the prototypes. Each prototype requires 5-8 hours of print time. With careful planning, 3 complete prototypes can be printed within a 24 hour period. Most of the prototypes are printed in the final week of the course, so the maximum production is approximately 21 complete blowers (which requires the course instructor to be available on the last weekend as well). Fortunately, a few groups print their models early (end of second to last week) which relieves some of the time pressure on the prototyping machine. The largest one semester load to complete the printing covered two course sections totaling 54 students and 18 projects. This is very close to the maximum number of groups that can be handled with a single prototyping machine.

The project has been repeated 4 times (4 semesters) without any substantial changes to the project statement. While this raises some possible concerns related to students sharing and using files from previous semesters, the instructors have not encountered such behavior.

\section{Assessment}

One of the shortcomings of the work related above is the absence of any rigorous assessment to analyze student learning and engagement. The project was implemented in an effort to create a more engaging course for undergraduates, but no measures were taken to formally document the outcomes. Anecdotal evidence suggests students are engaged in the project. Students develop initial designs using a number of modeling shortcuts to minimize their work. After the instructor provides feedback related to fluid flow, most groups rework their models to eliminate the shortcuts and build more efficient blowers. This is an indication of students engaging the material as well as students developing their own design rather than using a previously developed design. 


\section{Conclusion}

This paper has focused on the introduction of several technical engineering concepts through the use of a relatively simple, short term project in a freshman level engineering course. The design and prototyping of an air mattress inflation device exposes freshmen to engineering topics that include design for manufacturing, fluid dynamics, and structured experimentation. The technical information presented influences the designs created by the students thus demonstrating the ability of the students to engage the topics presented.

Freshman engineering courses serve as a critical educational gateway with the opportunity to introduce students to a variety of engineering topics. The topics introduced often shape the impressions that freshmen develop regarding their future engineering studies. While topics such as design process, reverse engineering, and solid modeling can provide a captivating freshman experience, they often undersell the student's desire to engage the engineering profession on a more technical level. Many feel that freshman are not prepared to deal with technical topics, or do not have the experience or coursework to properly handle these topics. Our experience with the blower project suggests quite the opposite. Even at the freshman level, students who are provided with technical information are keen to apply that information in their educational experience. Learning is, by nature, a cyclical process. The more technical exposure that can be provided to freshmen, the better those same students are likely to engage that same technical topic in their future studies.

\section{References}

1. Courter, S. S., Millar, S. B. and Lyons, L. (1998), From the Students' Point of View: Experiences in a Freshman Engineering Design Course. Journal of Engineering Education, 87: 283-288. doi: 10.1002/j.21689830.1998.tb00355.x

2. Dym, C. L. (1994), Teaching Design to Freshmen: Style and Content. Journal of Engineering Education, 83: 303-310. doi: 10.1002/j.2168-9830.1994.tb00123.x

3. Burton, J. D. and White, D. M. (1999), Selecting a Model for Freshman Engineering Design. Journal of Engineering Education, 88: 327-332. doi: 10.1002/j.2168-9830.1999.tb00454.x

4. Dally, J. W. and Zhang, G. M. (1993), A Freshman Engineering Design Course. Journal of Engineering Education, 82: 83-91. doi: 10.1002/j.2168-9830.1993.tb00081.x

5. Rutar, T. and Mason, G. (2005), A Learning Community of University Freshman Design, Freshman Graphics, and High School Technology Students: Description, Projects, and Assessment. Journal of Engineering Education, 94: 245-254. doi: 10.1002/j.2168-9830.2005.tb00845.x

6. Barr, R. E., Schmidt, P. S., Krueger, T. J. and Twu, C.-Y. (2000), An Introduction to Engineering Through an Integrated Reverse Engineering and Design Graphics Project. Journal of Engineering Education, 89: 413-418. doi: 10.1002/j.2168-9830.2000.tb00545.x 